\title{
Apoptosis commitment - translating survival signals into decisions on mitochondria
}

\author{
James A Keeble ${ }^{1}$, Andrew P Gilmore ${ }^{1}$ \\ ${ }^{1}$ Wellcome Trust Centre for Cell-Matrix Research, Faculty of Life Sciences, University of Manchester, A.3034 Michael Smith Building, \\ Oxford Road, Manchester M13 9PT, UK
}

\begin{abstract}
Most defective and unwanted cells die by apoptosis, an exquisitely controlled genetic programme for removing such cells without damaging the surrounding tissue. Once a cell has committed to apoptosis, the process is remarkably efficient, and is completed within a few minutes of initiation. This point of no return for an apoptotic cell is commonly held to be the point at which the outer mitochondrial membrane is permeabilised, a process regulated by the Bcl-2 family of proteins. How these proteins regulate this decision point is central to diseases such as cancer where apoptotic control is lost. In this review, we will discuss apoptotic signalling and how a cell makes the irreversible decision to die. We will focus on one set of survival signals, those derived by cell adhesion to the extracellular matrix (ECM), and use these to highlight the complexities of apoptotic signalling. In particular, we will illustrate how multiple signalling pathways converge to determine critical cell fate decisions.
\end{abstract}

Keywords: apoptosis, Bcl-2 proteins, anoikis, mitochondria, BH3-only proteins

Cell Research (2007) 17:976-984. doi: 10.1038/cr.2007.101; published online 11 December 2007

\section{Apoptosis, mitochondria and the Bcl-2 family}

Apoptosis in most cells is dependent on permeabilisation of the outer mitochondrial membrane (OMM) [1]. The intermembrane space of the mitochondria sequesters a number of proteins (e.g. cytochrome $c$ and Smac/Diablo) that, when released into the cytosol, activate caspases, the proteases that drive cellular execution [2]. Mitochondrial membrane permeabilisation (MMP) is controlled by proapoptotic and anti-apoptotic members of the Bcl-2 family [3]. These proteins are defined according to a number of shared Bcl-2 homology (BH) domains. Pro-survival proteins such as Bcl-2, Bcl- $\mathrm{X}_{\mathrm{L}}, \mathrm{Mcl}-1$ and Bcl-w share four regions of sequence homology (BH1-4). The pro-apoptotic proteins Bax, Bak and Bok share BH-domains 1-3. A further pro-apoptotic subgroup, the BH3-only proteins, has one BH-domain [4]. Overexpression of anti-apoptotic

Correspondence: Andrew P Gilmore

Tel: +44-161-275-3892; Fax: +44-161-275-1505

E-mail: agilmore@manchester.ac.uk members of the Bcl-2 family blocks MMP, whereas overexpression of pro-apoptotic ones can induce or sensitise cells to apoptosis.

Bcl-2 proteins reside directly upstream of MMP in the apoptotic programme (Figure 1). Although Bok, which has a very limited tissue distribution [5], probably has the same function, in most cells Bax and Bak are absolutely required for MMP [6]. Mice with a genetic deletion of either Bax or Bak are largely normal, and most cell types isolated from them are still able to undergo apoptosis in response to a wide range of stimuli. However, deletion of both Bax and Bak results in gross developmental abnormalities [7]. Furthermore, cells lacking both of these pro-apoptotic Bcl-2 family members will not undergo apoptotic cell death following the removal of survival factors [6]. Bax and Bak probably directly form the pores in the OMM, although how they do this is still a matter of considerable controversy. Recombinant Bax can form channels in synthetic lipid bilayers and in isolated mitochondria $[8,9]$. These channels appear to form transiently and be non-specific for the proteins that they allow through. Indeed, in vitro studies indicate Bax can release mega-dalton size dextrans from liposomes and 


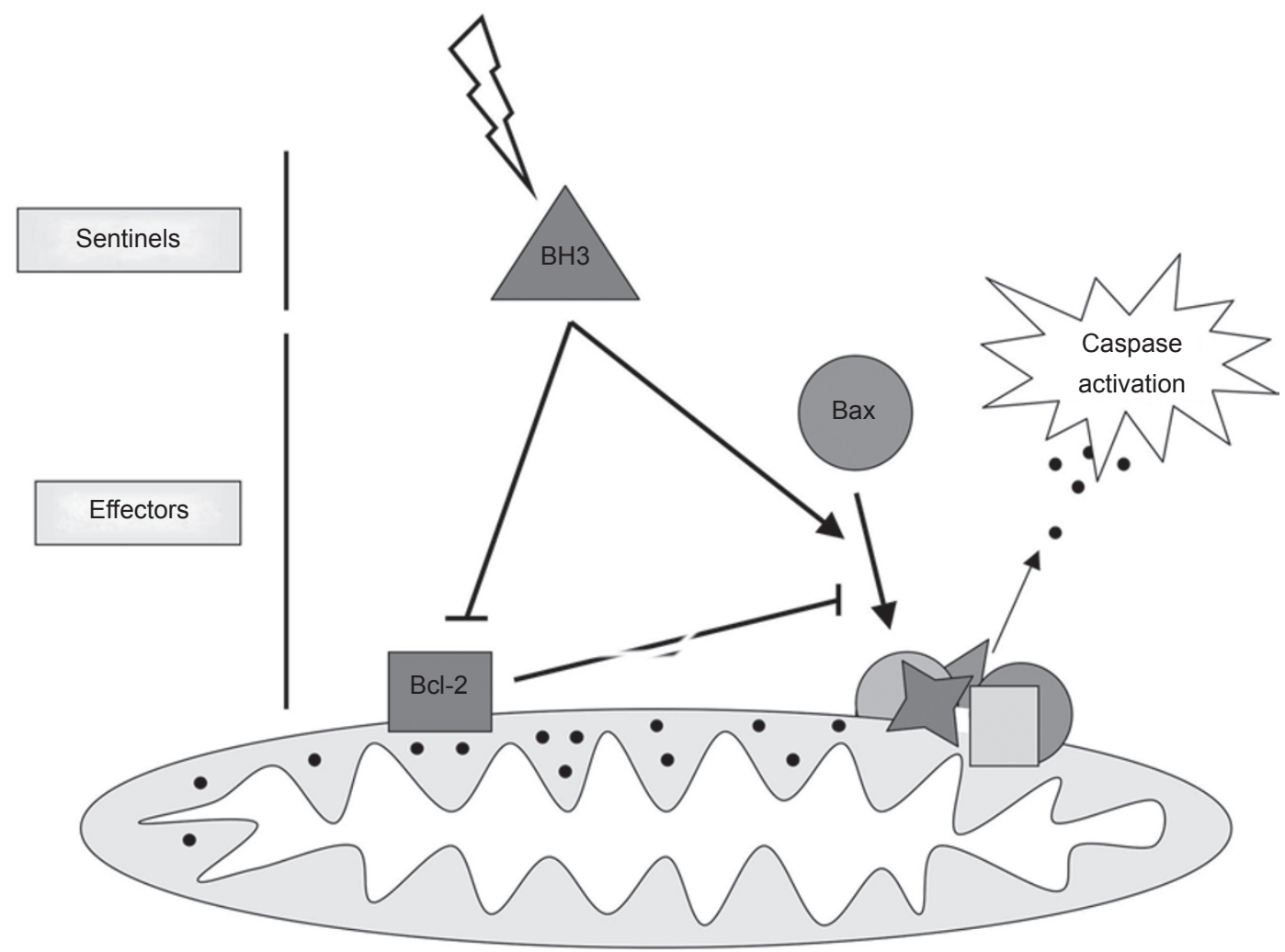

Figure 1 Apoptosis is regulated by the Bcl-2 family of proteins. Survival signalling maintains pro-apoptotic Bax as a monomer in the cytosol. When survival signals are lost Bax translocates to the outer mitochondrial membrane (OMM), where it is eventually activated. Activation coincides with permeabilisation of the OMM and the release of apoptogenic factors into the cytosol, leading to caspase activation. Bax activity is regulated by anti-apoptotic Bcl-2 family members and members of the pro-apoptotic BH3-only subfamily. Upon receipt of death stimuli, the levels of active BH3-only proteins increase. BH3-only proteins act as the sentinels in apoptosis. They may directly activate Bax or sensitise cells to apoptosis by inhibiting the function of anti-apoptotic members such as Bcl-2.

mitochondrial outer membrane vesicles. Time-lapse imaging of MMP indicates that it is an extremely rapid event. Within a single cell, all the mitochondria will release their cytochrome $c$ or Smac/Diablo within minutes of initiation [10-12]. Caspase activation and cell death follow MMP immediately [13]. Once the cell has decided to die, it does not waste any time about doing it.

In healthy cells, Bak is found integrated into the OMM [14]. In contrast, Bax is predominantly found in the cytosol and translocates to the OMM following an apoptotic signal $[13,15-18]$. Both proteins undergo a conformational change associated with MMP [12, 19-21]. The regulation of Bax is better understood than that of Bak. This is probably due to the fact that by being able to observe its translocation to mitochondria, Bax has proven more amenable to study. The current model of Bax activation is that a conformational change induces its oligomerisation and translocation to mitochondria, converting Bax into a membrane channel that facilitates MMP $[3,22]$. Bax, a cytosolic monomer in healthy cells, has a cryptic N-terminal epitope that becomes exposed when it translocates to mitochondria and oligomerises into high molecular weight complexes $[15,16,19$, 23]. Bak has also been shown to oligomerise and undergo a conformational change, so the mechanisms for activation are most likely very similar for both proteins. The nature of the channel, and in particular the components that make it up, is still a matter of considerable debate, and is discussed in depth elsewhere [24, 25].

Are Bax and Bak, and by implication Bok, activated in an all-or-nothing switch from inactive monomer to death inducing pore? Studies using essentially irreversible apoptotic stimuli (e.g. irradiation or staurosporine) have frequently implied this, a view that occasionally carries over into reviews and the general dogma [3]. However, it might not be expected that a cellular decision with such potentially drastic consequences if incorrect would be made in a single step. Indeed, evidence from several studies indicates Bax activation actually occurs in a series of discrete steps, 
some of which do not represent a point of commitment $[12,13]$. A difference between anoikis (apoptosis induced by detachment from ECM) and other cell culture models of apoptosis is that synchronous removal of a survival signal can be combined with subsequent reapplication of that signal prior to a cell committing to die [26]. Removal of cells from ECM results in loss of adhesion signalling via kinases such as focal adhesion kinase (FAK) within a few minutes (about which more will be explained below). Reattachment to ECM reactivates FAK within a similarly short time [27]. Following epithelial cell detachment from ECM, Bax translocates to the OMM within $15 \mathrm{~min}$, and reattachment to ECM results in its redistribution back to the cytosol [28]. Maintaining the loss of adhesion to ECM for a prolonged period is required for MMP, and it is only this later event that is accompanied by exposure of the cryptic Bax N-terminal epitope $[12,13]$. The details of this are published elsewhere, but the key point is that removal of survival signals may initially prime a cell for apoptosis, but subsequent signals are required for commitment to MMP. Other studies have also suggested that a "primed" apoptotic state exists in cancer cells [29]. Deciphering which signals regulate these distinct steps, potential cell death checkpoints, is important to understand how the process of apoptosis commitment occurs.

\section{ECM and survival signals}

Numerous signalling pathways have been described in the literature as the key to controlling Bax and Bak. However, viewed as a whole, the plethora of pathways, adaptor molecules and kinases does little to enlighten one regarding how the fundamental decision to exist or die is made. Perhaps by focusing on a subset of survival signals some clarity can be achieved.

Adhesion to the correct type of ECM is essential for the proliferation, differentiation and survival of most cells [30]. This ensures that cells only grow and differentiate within the correct context within a given tissue or organ. In the absence of the correct ECM, normal cells undergo an intrinsic programme of apoptosis termed anoikis (Greek for "homelessness") [31]. Anoikis is sometimes mentioned in the apoptosis literature as if it is a specific apoptotic signal [4]. However, the reality is somewhat different [26, 32]. Depending on the cell type, numerous signalling pathways can be activated by ECM adhesion, most of which are also implicated in other survival pathways.

The regulation of apoptosis by ECM was first described in two seminal papers from the groups of Steve Frisch and Martin Schwartz [33, 34]. These studies identified that ECM-dependent survival was mediated by integrins, a family of heterodimeric, transmembrane ECM receptors.
Humans have at least 24 different integrins, which arise through distinct dimeric combinations of the $18 \alpha$ and $8 \beta$ subunits identified to date [35]. Each integrin heterodimer can recognise several ECM proteins. Conversely, individual ECM molecules can bind to several different integrins. A cell's specificity for a particular ECM is, in part, dictated by the integrin heterodimers expressed on its surface. For example, mammary epithelial cells (MEC) adhere to the ECM molecule laminin, which is a major component of the basement membrane (BM) underlying the epithelial cell layer. MEC require adhesion to laminin via the $\alpha_{6} \beta_{1}$ integrin to suppress apoptosis $[36,37]$. In contrast, the stroma beneath the BM is composed primarily of collagen, which is unable to suppress MEC anoikis. This positional constraint can be overcome in metastatic cancer through the upregulation of integrins that support cell survival in environments that would be hostile to non-transformed cells. For example, invasive melanoma cells acquire $\alpha_{v} \beta_{3}$ integrin expression, allowing them to survive within the dermal collagen [38, 39].

Integrins have a dynamic intracellular signalling role and when ligated to the correct ECM activate numerous signalling pathways. Integrins cluster in the plane of the membrane at the sites of cell-ECM contact into large cytoskeletal assemblies termed focal adhesions [40]. Integrins are devoid of enzymatic activity and rely on recruiting signalling proteins through the use of adaptor molecules. Thus, clustering into focal adhesions results in the recruitment of adaptor proteins and signalling enzymes to the intracellular domain of integrins. Two prominent signalling enzymes specific for integrin-dependent signalling are FAK [41] and integrin-linked kinase (ILK) [42].

FAK is a non-receptor tyrosine kinase that has been shown in several studies to play a pivotal role in cell survival. Constitutively active FAK can suppress anoikis in detached cells [31]. Conversely, apoptosis can be induced in adherent cells by expression of a dominant-negative FAK or by microinjection of anti-FAK antibodies [28, 43, 44]. Upon ligation with the correct ECM, integrins recruit FAK which autophosphorylates on tyrosine 397 [41]. This event activates FAK and results in the recruitment of various other kinases and adaptor proteins to the signalling complex, a process not dissimilar from growth factor receptor activation. Indeed, although FAK itself is specific to integrin signalling, the pathways activated downstream are distinctly familiar from growth factor signalling, including Src family kinases, PI3K, Akt, MAPKinases and GTPases (Figure 2A). Interestingly, it appears that even though FAK is a key mediator of integrin-dependent survival signals, in different cell types it activates different downstream pathways (Zouq and Gilmore, unpublished results). Thus, depending on the cellular context, activation of FAK can 
A

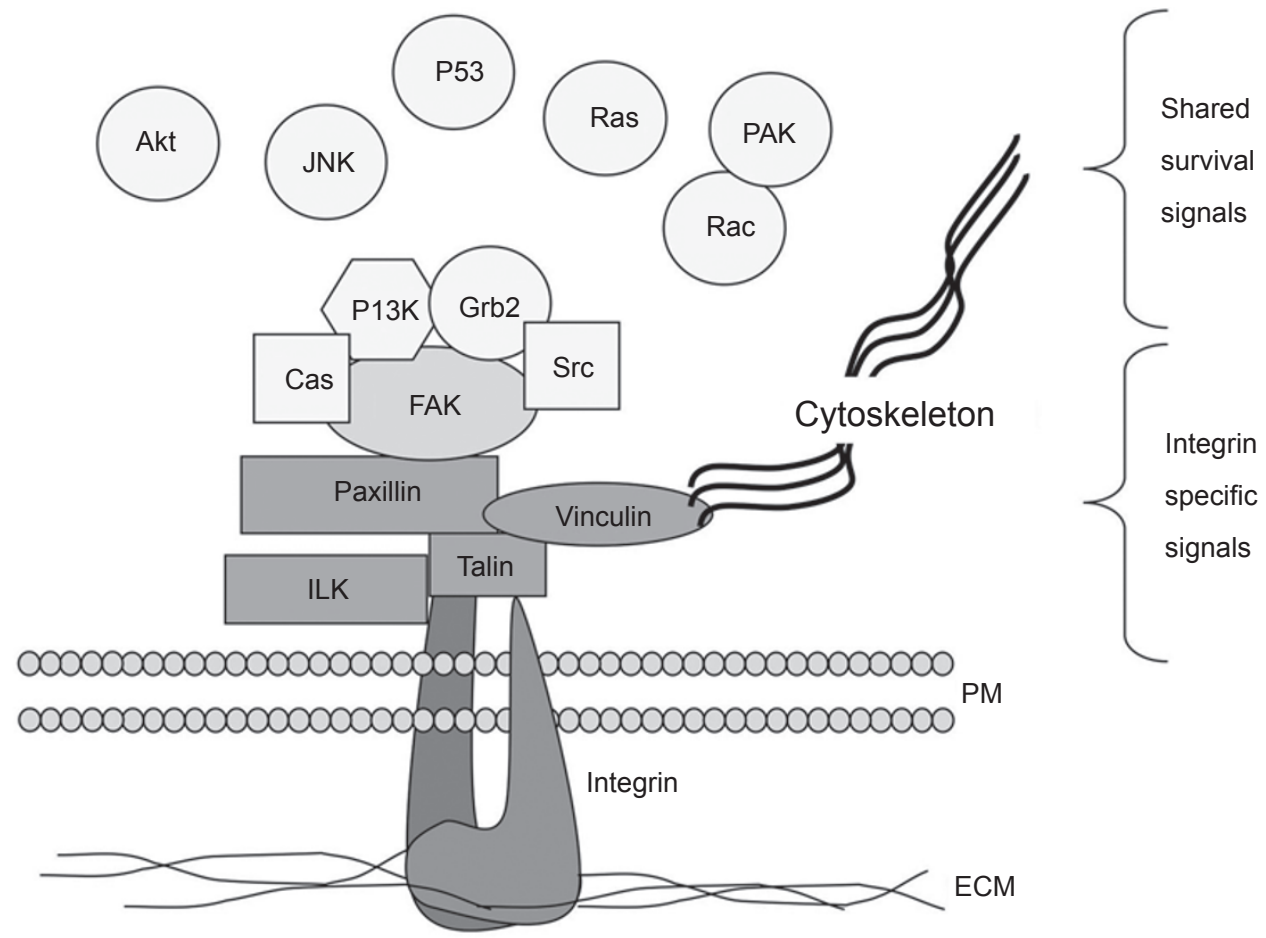

B

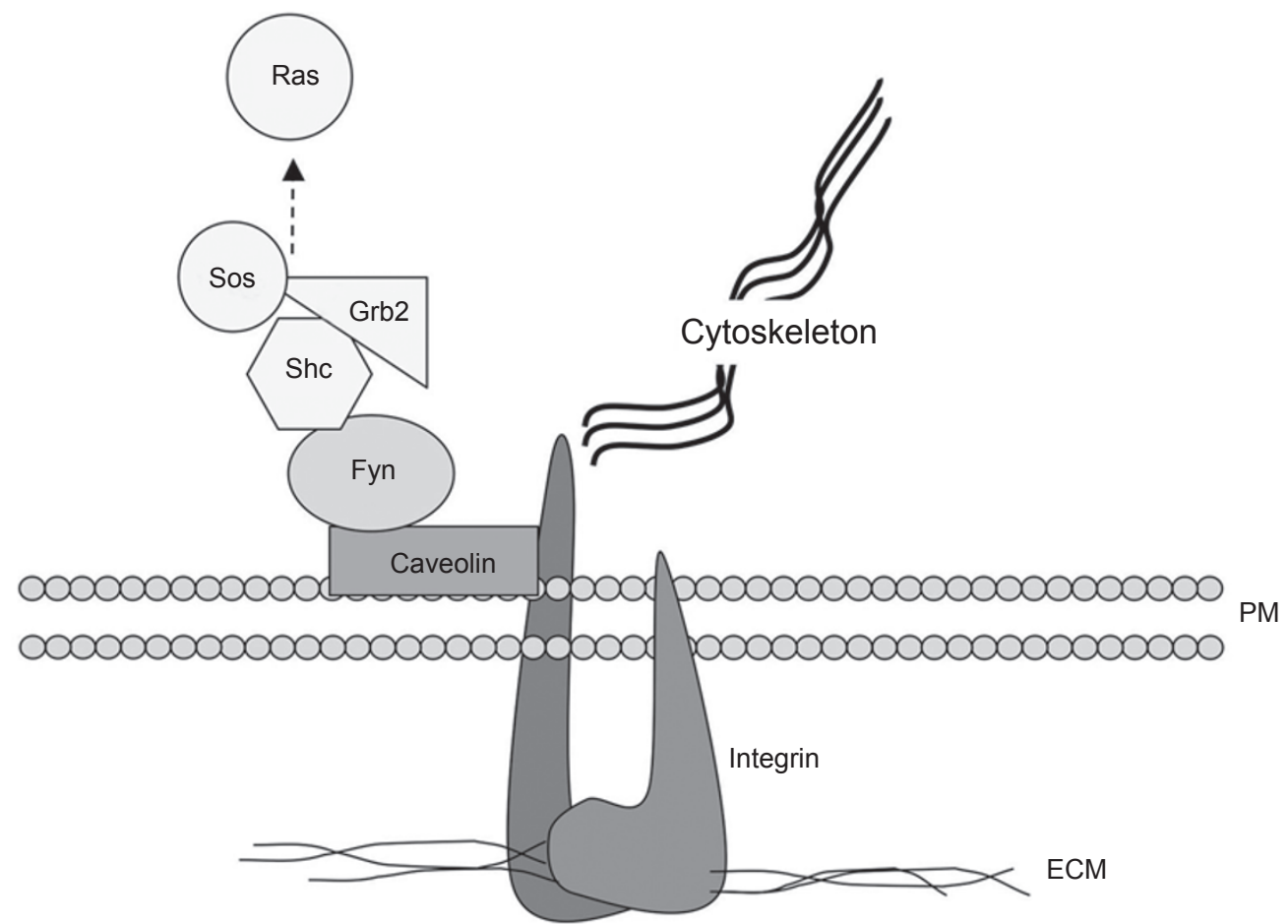

Figure 2 Adhesion-dependent survival signalling. Integrins physically link cells to the extracellular matrix and have a dynamic signalling role. The cytoplasmic tails of integrins are devoid of enzymatic activity and are connected to intracellular signalling components through the recruitment of adaptor proteins. (A) The majority of integrins bind adaptor proteins such as paxillin and talin. These in turn recruit signalling kinases such as FAK and ILK to the complex. These represent signalling pathways that are specific to integrins. FAK and ILK can activate numerous downstream survival pathways, including, PI3K-Akt, Rac-PAK, Ras and JNK. These downstream effectors are common to numerous survival pathways, and are not specific to integrins and anoikis. (B) $\alpha_{v} \beta_{3}$ integrins propagate cell-survival signals using a distinct signalling complex. This pathway is independent of FAK and ILK and involves the recruitment of the Src family kinases Yes and Fyn via an interaction with caveolin-1. Once recruited to integrins, Yes and Fyn can activate the Ras-ERK survival pathway through interactions with Shc, Grb-2 and Sos. 
signal via a number of known survival pathways. One study using MDCK cells identified that the loss of FAK signalling resulted in the activation of JNK, which was required for anoikis [45]. However, a different study indicated that PI3-kinase activation in adherent cells was required to suppress apoptosis, and that JNK did not play a role $[46,47]$. Conversely, in adherent fibroblasts FAK has been shown to signal via JNK to keep cells alive by suppressing p53, whereas there was no role of FAK-dependent activation of PI3-kinase [44, 48].

Although most integrins can recruit and activate FAK, it is not the only mechanism by which they can initiate signalling. ILK has been implicated in integrin-mediated survival, and is linked to Akt signalling [49]. ILK can enhance phosphorylation of Akt on threonine 308, which, in combination with serine 473 phosphorylation, is essential for Akt activity. Overexpression of ILK can increase Akt activity and suppress anoikis in some cells. Further variations in integrin signalling are seen with $\alpha_{\mathrm{V}}$ integrins (Figure 2B) [50]. They utilise a distinct signalling pathway independent of FAK and ILK, which involves the recruitment of the Src family kinases Yes and Fyn via an interaction with caveolin-1 [51]. Once recruited to integrins, Yes and Fyn can activate the Ras-ERK signalling pathway through interactions with Shc, Grb-2 and Sos.

Clearly, how an integrin signals to keep a cell alive very much depends on cell type and the ECM context, factors that can be greatly altered during processes such as cell transformation. How, then is all this translated into mitochondrial events?

\section{BH3-only proteins - linking survival signals to mi- tochondria}

The BH3-only subfamily of the Bcl-2 family provides the link between survival signals and Bax and Bak [4]. $\mathrm{BH} 3$-only proteins comprise the most diverse group of the Bcl-2 family, and by themselves are unable to induce MMP. Instead, they regulate the activities of the both the pro- and anti-apoptotic multidomain family members. Consequently, BH3-only proteins are unable to induce MMP in cells lacking Bax and Bak [6]. Furthermore, whereas Bax and Bak are activated by most apoptotic signals, $\mathrm{BH} 3$-only proteins each appear to respond to a restricted set of stimuli. For example, growth factor signalling regulates $\operatorname{Bim}[52,53]$ and Bad [54-56], whereas Puma [57, 58] and Noxa [59, 60] are transcriptionally upregulated by $\mathrm{p} 53$. The response of different $\mathrm{BH} 3$-proteins to distinct apoptotic stimuli suggests that a specific insult will result in the activation of a subset of BH3-proteins. Consequently, BH3-only proteins are thought to act as sentinels, monitoring cellular well being and regulating the activation of Bax and Bak.
Several BH3-only proteins have been proposed to be the key initiators of anoikis. Bim [61, 62], Bad [63], Bmf [64, 65] and Bid [66] have all been directly implicated. Furthermore, all have been shown to regulate anoikis in MEC. Bim can regulate anoikis in vitro and in vivo in MEC [61, $62]$. In the mammary gland, MEC form three-dimensional secretory acini required for milk production during lactation. The hollow lumen of these structures is in part formed when the cells in the centre of the developing acini lose contact with the surrounding ECM and die through anoikis. Correct formation of the lumen is disrupted in both Bim $-/-$ mice, and in an MCF10A cell culture model in which Bim has been knocked down with siRNA. In these models, Bim is regulated at the transcriptional level downstream of epidermal growth factor (EGF) signalling. Inhibiting integrin/ECM adhesion leads to loss of cell surface EGF receptor, and subsequent increase in Bim expression. Similarly, siRNA knockdown of Bmf also reduced MCF10A sensitivity to anoikis [65]. In another study, knockdown of Bid in a murine MEC line inhibited anoikis, and Bid was shown to be regulated post-translationally by ECM adhesion [66]. Confusingly, knockdown of Bid did not affect the human MCF10A model, and knockdown of Bim did not affect the murine cell model. Again, cell type and context can alter the apparent mechanism by which a superficially similar signal is translated into an apoptotic response. A further study indicated that primary MEC isolated from Bad $-/-$ mice were now able to survive on collagen, an ECM that normally does not provide a survival signal to these cells [67]. It would appear, therefore, that one could manipulate almost any $\mathrm{BH} 3$-only protein and inhibit MEC anoikis in the correct circumstances.

An emerging model of $\mathrm{Bcl}-2$ protein function may explain this [68]. The anti-apoptotic members of the Bcl-2 family may function by binding and sequestering activated BH3-only proteins [69]. If the anti-apoptotic proteins are inhibited, then the BH3-protein can activate Bax and MMP. Different $\mathrm{BH} 3$-only proteins may preferentially regulate distinct multi-domain Bcl-2 family members [70, 71]. Different BH3-only proteins may either activate Bax and Bak or inactivate anti-apoptotic proteins like $\mathrm{Bcl}_{\mathrm{L}} \mathrm{X}_{\mathrm{L}}$ and Mcl-1. Thus, Bid and Bim can function as "activators", being able to directly "turn on" Bax and Bak, whereas others such as Bad, Bmf and Noxa act as "sensitisers" (Figure $3)$. The result of turning on a "sensitiser" BH3-protein is to remove the inhibitory effect of pro-survival Bcl-2 proteins, allowing the "activators" Bid and Bim to turn on Bax. Furthermore, the senstisers can have distinct affinities for the different anti-apoptotic proteins [29]. Bad can inhibit Bcl-2, Bcl- $\mathrm{X}_{\mathrm{L}}$ and Bcl-w, but cannot inhibit Mcl-1. In contrast, Noxa antagonises Mcl-1 but has no effect on $\mathrm{Bcl}-2, \mathrm{Bcl}-\mathrm{X}_{\mathrm{L}}$ or Bcl-w. Other BH3-only proteins show 
overlapping patterns of activity. It becomes apparent that signalling inputs that alter "senistiser" $\mathrm{BH} 3$-only proteins will adjust the threshold for the decision to undergo MMP if the "activators" themselves get switched on.

If this model is correct, it might explain the numerous conflicting studies of anoikis in epithelial cells. Bad-deficient MEC did not die following attachment to collagen as the threshold for apoptosis had been significantly raised. Changes in Bad phosphorylation in response to growth factors have been demonstrated to alter the threshold for other apoptotic signals to induce cell death [56]. Knockdown of Bmf, similarly, resulted in MCF10A cells becoming resistant to anoikis. Thus, even though loss of adhesion signals may lead to activation of Bim or Bid, the reduction in "sensitiser" BH3-proteins allows anti-apoptotic Bcl-2 proteins to inhibit their function and the cell does not progress to MMP. Experimental alterations in the BH3-protein milieu could therefore alter the perception of the apoptotic pathway involved in anoikis.
The BH3-protein-dependent threshold for anoikis could be affected by many signals independent of adhesion (growth factors, oncogene activation, DNA damage). Bim has been shown to be upregulated in MCF10A cells via downregulation of EGF receptor signalling [61]. EGF receptor family members, such as Erb2, are frequently overexpressed in breast cancer, and thus may affect the ability of invasive cancer cells to evade anoikis [72]. Upregulation of another tyrosine kinase receptor, TrkB (a neurotrophic growth factor receptor that is not activated by cell adhesion), has been shown to produce anoikis resistance in a non-malignant rat intestinal epithelial cell line that was otherwise extremely sensitive to loss of adhesion [73]. These cells were then able to form multiple metastases following intravenous injection into nude mice. Yet another example is Notch signalling, which is also upregulated in many primary breast tumours [74]. Constitutive Notch activation resulted in MCF10A cells becoming resistant to DNA-damaging agents, growth factor inhibition and

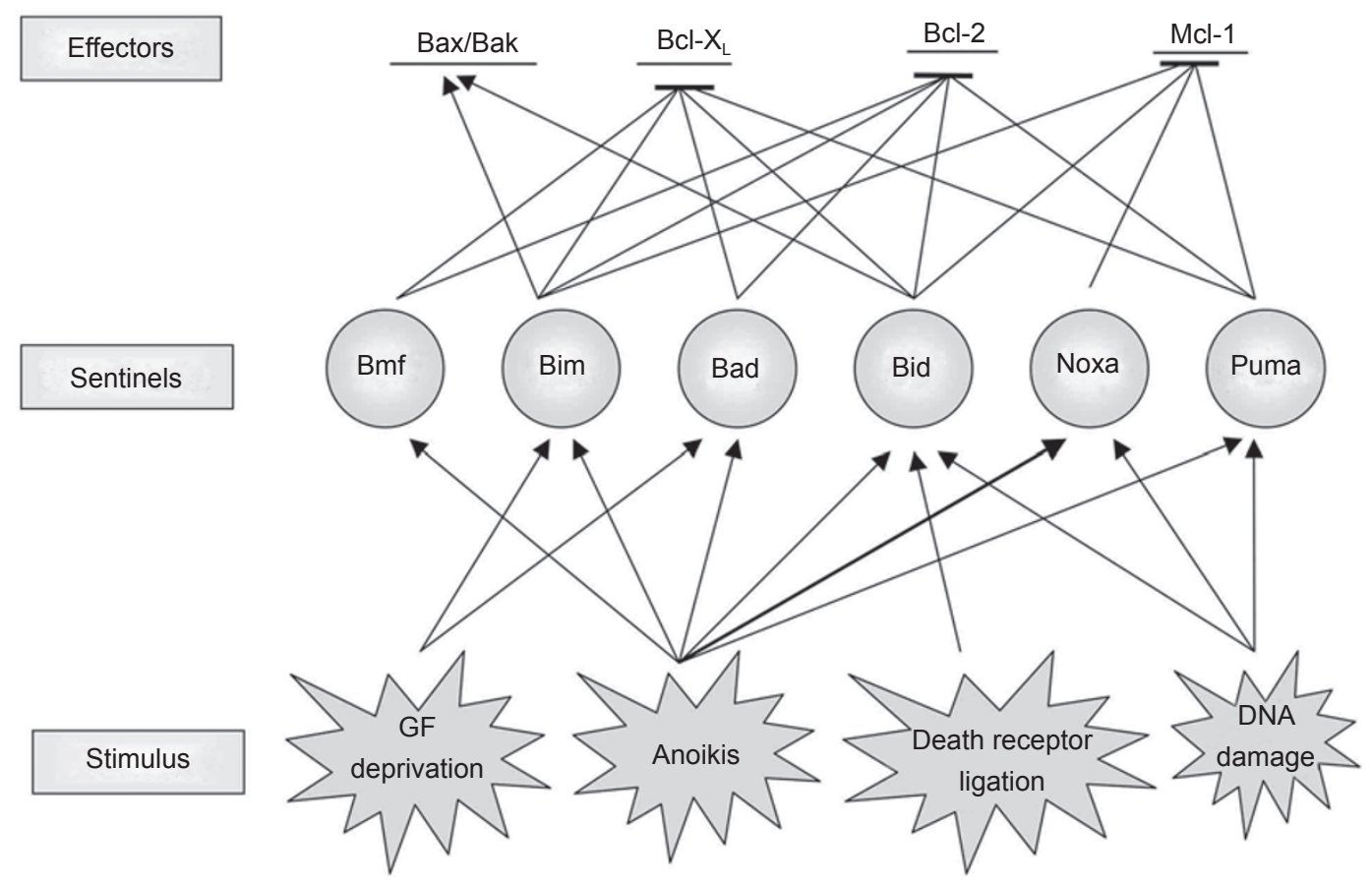

Figure 3 The BH3-only proteins link survival signals to mitochondrial events. BH3-only proteins monitor cellular well being and are responsive to a variety of stimuli. Acting as the sentinels of apoptosis, they are activated in response to growth factor (GF) deprivation, anoikis, death receptor ligation and DNA damage. Their activation in response to death signals results either in the inhibition of anti-apoptotic family members, thereby sensitising a cell to apoptosis, or in the direct activation of pro-apoptotic Bak and Bax. Bim can be activated in response to anoikis and GF withdrawal, and can directly activate Bax and inhibit all anti-apoptotic Bcl-2 family members. Bid is activated in response to anoikis as well as DNA damage and death receptor ligation. Like Bim, Bid can directly activate Bax and inhibit anti-apoptotic family members. Bad and Bmf more specifically interact with $\mathrm{Bcl}-2$ and $\mathrm{Bcl}-\mathrm{X}_{\mathrm{L}}$, while Noxa binds Mcl-1. Bad binds and inactivates Bcl-2 in response to cytokine deprivation, while anoikis activates Bmf. Puma and Noxa transcripts are upregulated via a p53-dependent signal, particularly following DNA damage. Such apparent complexities in interactions suggest that the ultimate decision of whether Bax and Bak induce OMM permeabilisation is the sum of numerous survival inputs that regulate the entire $\mathrm{BH} 3$-protein milieu. 
anoikis. Thus, altering a known survival pathway may lead to resistance to other, diverse, apoptotic signals.

\section{Apoptosis commitment - is it all about Bcl-2 family members?}

The current favoured model for apoptosis initiation suggests that the decision making of cell death is undertaken by interactions between Bcl-2 family members. BH3-only proteins can bind and activate Bax and Bak or inactivate their anti-apoptotic relatives. Actually, a number of unanswered questions remain, and suggest that interactions with other mitochondrial proteins may be just as important for regulating Bcl-2 family function. For example, Ku70 interacts with the $\mathrm{N}$-terminus of Bax, and appears to prevent its translocation to mitochondria [75]. Cytosolic p53 has also been shown to be able to activate Bax [76].

Bax forms complexes on mitochondria during apoptosis $[13,23]$. Possible Bax binding partners on the OMM include components of the permeability transition pore such as the voltage-dependent anion channel (VDAC) [1, 77]. Although some studies have indicated that Bax might regulate the activity of VDAC, conversely VDAC may control Bax activation. Indeed, Bak on the OMM has been shown to bind VDAC2, an interaction proposed to keep Bak inactive in healthy cells [78]. Bid can displace Bak from VDAC2 and lead to its activation. Although it is not yet known whether interactions with mitochondrial proteins keep Bax inactive, a number of anti-apoptotic viral proteins do. M11L and vMIA bind Bax on mitochondria, preventing Bax N-terminal epitope exposure and cytochrome c release [79-81].

Interactions with mitochondrial components may be required to initially target Bcl-2 family members to the OMM, bringing them near to other family members so that they can interact. Activated Bid has been shown to interact with the OMM protein $\mathrm{MTCH} 2$, an interaction proposed to be required for Bid to target to mitochondria $[82,83]$. Interactions with mitochondrial lipids may also have a role in targeting Bid [84]. Interestingly, the region of Bid that can localise to the OMM is independent of the BH3-domain that can interact with the other Bcl-2 family members [66]. Bad has well-characterised interactions with OMM proteins, such as glucokinase [85]. At present, little is known about how such interactions with OMM components may be regulated, or in the case of most Bcl-2 family members, what those interacting partners are. However, some other cell signalling pathways provide an interesting comparison. Not that many years ago, MAPK signalling was understood as a linear cascade of MAPkinases, MAPkinase kinases and MAPkinase kinase kinases. It is now becoming increasingly clear that MAPKs are regulated through interactions with adaptor and scaffold proteins that restrict the signalling components to specific subcellular compartments [86]. Kinase suppressor of Ras is an excellent example, and is required to bring Ras, MEK and ERK together at the plasma membrane. Bad is regulated by phosphorylation, and one of the kinases (PKA) is specifically recruited to the OMM in a scaffold complex with mitochondrial proteins [87], suggesting that a similar model for $\mathrm{Bcl}-2$ family regulation may exist. At present some major strides in understanding apoptosis are focused on the interactions between the multi-domain Bcl-2 family members and the "activator" and "suppressor" BH3-proteins. However, we should not be surprised if this represents only a part of the complexities of apoptosis commitment, and other equally important levels of regulation are found. Importantly, it is insights into these complexities that are starting to shed light on how we may therapeutically manipulate apoptosis in diseases where its regulation has gone awry.

\section{Acknowledgments}

The authors would like to thank Anthony Valentijn (Manchester University, UK) for comments on the manuscript. Work in the authors' laboratory is funded by the Wellcome Trust, the Breast Cancer Campaign and Cancer Research UK. JK is the recipient of a BBSRC postgraduate training award.

\section{References}

1 Martinou JC, Green DR. Breaking the mitochondrial barrier. Nat Rev Mol Cell Biol 2001; 2:63-67.

2 Green DR. Apoptotic pathways: ten minutes to dead. Cell 2005; 121:671-674.

3 Cory S, Adams JM. The Bcl2 family: regulators of the cellular life-or-death switch. Nat Rev Cancer 2002; 2:647-656.

4 Bouillet P, Strasser A. BH3-only proteins - evolutionarily conserved proapoptotic Bcl-2 family members essential for initiating programmed cell death. J Cell Sci 2002; 115 Part 8:1567-1574.

5 Hsu SY, Kaipia A, McGee E, Lomeli M, Hsueh AJ. Bok is a proapoptotic Bcl-2 protein with restricted expression in reproductive tissues and heterodimerizes with selective anti-apoptotic Bcl-2 family members. Proc Natl Acad Sci USA 1997; 94:1240112406.

6 Wei MC, Zong WX, Cheng EH, et al. Proapoptotic BAX and BAK: a requisite gateway to mitochondrial dysfunction and death. Science 2001; 292:727-730.

7 Lindsten T, Ross AJ, King A, et al. The combined functions of proapoptotic Bcl-2 family members bak and bax are essential for normal development of multiple tissues. Mol Cell 2000; 6:1389-1399.

8 Kuwana T, Mackey MR, Perkins G, et al. Bid, Bax, and lipids cooperate to form supramolecular openings in the outer mitochondrial membrane. Cell 2002; 111:331-342.

9 Saito M, Korsmeyer SJ, Schlesinger PH. BAX-dependent trans- 
port of cytochrome $c$ reconstituted in pure liposomes. Nat Cell Biol 2000; 2:553-555.

10 Goldstein JC, Waterhouse NJ, Juin P, Evan GI, Green DR. The coordinate release of cytochrome $c$ during apoptosis is rapid, complete and kinetically invariant. Nat Cell Biol 2000; 2:156162.

11 Rehm M, Dussmann H, Janicke RU, et al. Single-cell fluorescence resonance energy transfer analysis demonstrates that caspase activation during apoptosis is a rapid process. Role of caspase-3. J Biol Chem 2002; 277:24506-24514.

12 Upton JP, Valentijn AJ, Gilmore AP. The N-terminal conformation of Bax regulates cell commitment to apoptosis. Cell Death Differ 2007; 14:932-942.

13 Valentijn AJ, Metcalfe AD, Kott J, Streuli CH, Gilmore AP. Spatial and temporal changes in Bax subcellular localization during anoikis. J Cell Biol 2003; 162:599-612.

14 Nechushtan A, Smith CL, Lamensdorf I, Yoon SH, Youle RJ. Bax and Bak coalesce into novel mitochondria-associated clusters during apoptosis. J Cell Biol 2001; 153:1265-1276.

15 Hsu YT, Wolter KG, Youle RJ. Cytosol-to-membrane redistribution of Bax and Bcl-X(L) during apoptosis. Proc Natl Acad Sci USA 1997; 94:3668-3672.

16 Wolter KG, Hsu YT, Smith CL, et al. Movement of Bax from the cytosol to mitochondria during apoptosis. J Cell Biol 1997; 139:1281-1292.

17 Gross A, Jockel J, Wei MC, Korsmeyer SJ. Enforced dimerization of BAX results in its translocation, mitochondrial dysfunction and apoptosis. EMBO J 1998; 17:3878-3885.

18 Goping IS, Gross A, Lavoie JN, et al. Regulated targeting of BAX to mitochondria. J Cell Biol 1998; 143:207-215.

19 Desagher S, Osen Sand A, Nichols A, et al. Bid-induced conformational change of Bax is responsible for mitochondrial cytochrome $c$ release during apoptosis. J Cell Biol 1999; 144:891901.

20 Nechushtan A, Smith CL, Hsu YT, Youle RJ. Conformation of the Bax C-terminus regulates subcellular location and cell death. EMBO J 1999; 18:2330-2341.

21 Griffiths GJ, Dubrez L, Morgan CP, et al. Cell damage-induced conformational changes of the pro-apoptotic protein Bak in vivo precede the onset of apoptosis. J Cell Biol 1999; 144:903-914.

22 Danial NN, Korsmeyer SJ. Cell death: critical control points. Cell 2004; 116:205-219.

23 Antonsson B, Montessuit S, Sanchez B, Martinou JC. Bax is present as a high molecular weight oligomer/complex in the mitochondrial membrane of apoptotic cells. J Biol Chem 2001; 276:11615-11623.

24 Antignani A, Youle RJ. How do Bax and Bak lead to permeabilization of the outer mitochondrial membrane? Curr Opin Cell Biol 2006; 18:685-689.

25 Zamzami N, Kroemer G. Apoptosis: mitochondrial membrane permeabilization - the (W)hole story? Curr Biol 2003; 13:R71R73.

26 Gilmore AP. Anoikis. Cell Death Differ 2005; 12 Suppl 2:14731477.

27 Burridge K, Turner CE, Romer LH. Tyrosine phosphorylation of paxillin and pp125FAK accompanies cell adhesion to extracellular matrix: a role in cytoskeletal assembly. J Cell Biol 1992; 119:893-903.

28 Gilmore AP, Metcalfe AM, Romer LH, Streuli CH. Integrinmediated survival signals regulate the apoptotic function of Bax through its conformation and subcellular localization. J Cell Biol 2000; 149:431-445.

29 Certo M, Del Gaizo Moore V, Nishino M, et al. Mitochondria primed by death signals determine cellular addiction to antiapoptotic BCL-2 family members. Cancer Cell 2006; 9:351-365.

30 Schwartz MA. Integrins, oncogenes, and anchorage independence. J Cell Biol 1997; 139:575-578.

31 Frisch SM, Vuori K, Ruoslahti E, Chanhui PY. Control of adhesion-dependent cell-survival by focal adhesion kinase. J Cell Biol 1996; 134:793-799.

32 Frisch SM, Screaton RA. Anoikis mechanisms. Curr Opin Cell Biol 2001; 13:555-562.

33 Frisch SM, Francis H. Disruption of epithelial cell-matrix interactions induces apoptosis. J Cell Biol 1994; 124:619-626.

34 Meredith JE, Fazeli B, Schwartz MA. The extracellular-matrix as a cell-survival factor. Mol Biol Cell 1993; 4:953-961.

35 Hynes RO. Integrins: bidirectional, allosteric signaling machines. Cell 2002; 110:673-687.

36 Pullan S, Wilson J, Metcalfe A, et al. Requirement of basement membrane for the suppression of programmed cell death in mammary epithelium. J Cell Sci 1996; 109:631-642.

37 Streuli CH, Farrelly H, Lee YJ, et al. The control of apoptosis through cell-stromal interactions. J Pathol 1998; 186:A16.

38 Montgomery AMP, Reisfeld RA, Cheresh DA. Integrinalpha(V)beta(3) rescues melanoma-cells from apoptosis in 3-dimensional dermal collagen. ProcNatl Acad Sci USA 1994; 91:8856-8860.

39 Petitclerc E, Stromblad S, vonSchalscha TL, et al. Integrin alpha(V)beta(3) promotes M21 melanoma growth in human skin by regulating tumor cell survival. Cancer Res 1999; 59:27242730 .

40 Zamir E, Geiger B. Molecular complexity and dynamics of cellmatrix adhesions. J Cell Sci 2001; 114 Part 20:3583-3590.

41 Parsons JT. Focal adhesion kinase: the first ten years. J Cell Sci 2003; 116 Part 8:1409-1416.

42 Dedhar S. Cell-substrate interactions and signaling through ILK. Curr Opin Cell Biol 2000; 12:250-256.

43 Hungerford JE, Compton MT, Matter ML, Hoffstrom BG, Otey CA. Inhibition of pp125FAK in cultured fibroblasts results in apoptosis. J Cell Biol 1996; 135:1383-1390.

44 Ilic D, Almeida EAC, Schlaepfer DD, et al. Extracellular matrix survival signals transduced by focal adhesion kinase suppress p53-mediated apoptosis. J Cell Biol 1998; 143:547-560.

45 Frisch SM, Vuori K, Kelaita D, Sicks S. A role for Jun-N-terminal kinase in anoikis - suppression by Bcl-2 and Crma. J Cell Biol 1996; 135: 1377-1382.

46 Khwaja A, Rodriguez Viciana P, Wennstrom S, Warne PH, Downward J. Matrix adhesion and Ras transformation both activate a phosphoinositide 3-OH kinase and protein kinase B/Akt cellular survival pathway. EMBO J 1997; 16:2783-2793.

47 Khwaja A, Downward J. Lack of correlation between activation of Jun-NH2-terminal kinase and induction of apoptosis after detachment of epithelial cells. J Cell Biol 1997; 139:1017-1023.

48 Almeida EA, Ilic D, Han Q et al. Matrix survival signaling: from fibronectin via focal adhesion kinase to c-Jun $\mathrm{NH}(2)$-terminal kinase. J Cell Biol 2000; 149:741-754.

49 Attwell S, Roskelley C, Dedhar S. The integrin-linked kinase (ILK) suppresses anoikis. Oncogene 2000; 19:3811-3815.

50 Giancotti FG. Complexity and specificity of integrin signalling. Nat Cell Biol 2000; 2:E13-E14. 
51 Wary KK, Mariotti A, Zurzolo C, Giancotti FG. A requirement for caveolin-1 and associated kinase Fyn in integrin signaling and anchorage-dependent cell growth. Cell 1998; 94:625-634.

52 Ley R, Balmanno K, Hadfield K, Weston C, Cook SJ. Activation of the ERK1/2 signaling pathway promotes phosphorylation and proteasome-dependent degradation of the $\mathrm{BH} 3$-only protein, Bim. J Biol Chem 2003; 278:18811-18816.

53 Gilley J, Coffer PJ, Ham J. FOXO transcription factors directly activate bim gene expression and promote apoptosis in sympathetic neurons. J Cell Biol 2003; 162:613-622.

54 delPeso L, Gonzalez Garcia M, Page C, Herrera R, Nunez G. Interleukin-3-induced phosphorylation of BAD through the protein kinase Akt. Science 1997; 278:687-689.

55 Gilmore AP, Valentijn AJ, Wang P, et al. Activation of BAD by therapeutic inhibition of epidermal growth factor receptor and transactivation by insulin-like growth factor receptor. J Biol Chem 2002; 277:27643-27650.

56 Datta SR, Ranger AM, Lin MZ, et al. Survival factor-mediated BAD phosphorylation raises the mitochondrial threshold for apoptosis. Dev Cell 2002; 3:631-643.

57 Nakano K, Vousden KH. PUMA, a novel proapoptotic gene, is induced by p53. Mol Cell 2001; 7:683-694.

58 Hemann MT, Zilfou JT, Zhao Z, et al. Suppression of tumorigenesis by the p53 target PUMA. Proc Natl Acad Sci USA 2004; 101:9333-9338.

59 Shibue T, Takeda K, Oda E, et al. Integral role of Noxa in p53mediated apoptotic response. Genes Dev 2003; 17:2233-2238.

60 Oda E, Ohki R, Murasawa H, et al. Noxa, a BH3-only member of the Bcl-2 family and candidate mediator of p53-induced apoptosis. Science 2000; 288:1053-1058.

61 Reginato MJ, Mills KR, Paulus JK, et al. Integrins and EGFR coordinately regulate the pro-apoptotic protein Bim to prevent anoikis. Nat Cell Biol 2003; 5:733-740.

62 Mailleux AA, Overholtzer M, Schmelzle T, et al. BIM regulates apoptosis during mammary ductal morphogenesis, and its absence reveals alternative cell death mechanisms. Dev Cell 2007; 12:221-234.

63 Idogawa M, Adachi M, Minami T, Yasui H, Imai K. Overexpression of BAD preferentially augments anoikis. Int J Cancer 2003; 107:215-223.

64 Puthalakath H, Villunger A, O'Reilly LA, et al. Bmf: a proapoptotic $\mathrm{BH} 3$-only protein regulated by interaction with the myosin $\mathrm{V}$ actin motor complex, activated by anoikis. Science 2001; 293:1829-1832.

65 Schmelzle T, Mailleux AA, Overholtzer M, et al. Functional role and oncogene-regulated expression of the $\mathrm{BH} 3$-only factor Bmf in mammary epithelial anoikis and morphogenesis. Proc Natl Acad Sci USA 2007; 104:3787-3792.

66 Valentijn AJ, Gilmore AP. Translocation of full-length bid to mitochondria during Anoikis. J Biol Chem 2004; 279:3284832857.

67 Ranger AM, Zha J, Harada H, et al. Bad-deficient mice develop diffuse large B cell lymphoma. Proc Natl Acad Sci USA 2003; 100:9324-9329.

68 Green DR. At the gates of death. Cancer Cell 2006; 9:328330.

69 Cheng EH, Wei MC, Weiler S, et al. BCL-2, BCL-X(L) sequester $\mathrm{BH} 3$ domain-only molecules preventing BAX-and BAK-mediated mitochondrial apoptosis. Mol Cell 2001; 8:705-711.
70 Letai A, Bassik MC, Walensky LD, et al. Distinct BH3 domains either sensitize or activate mitochondrial apoptosis, serving as prototype cancer therapeutics. Cancer Cell 2002; 2:183-192.

71 Kim H, Rafiuddin-Shah M, Tu HC, et al. Hierarchical regulation of mitochondrion-dependent apoptosis by BCL-2 subfamilies. Nat Cell Biol 2006; 8:1348-1358.

72 Olayioye MA, Neve RM, Lane HA, Hynes NE. The ErbB signaling network: receptor heterodimerization in development and cancer. EMBO J 2000; 19:3159-3167.

73 Douma S, Van Laar T, Zevenhoven J, et al. Suppression of anoikis and induction of metastasis by the neurotrophic receptor TrkB. Nature 2004; 430:1034-1039.

74 Stylianou S, Clarke RB, Brennan K. Aberrant activation of notch signaling in human breast cancer. Cancer Res 2006; 66:15171525.

75 Sawada M, Sun W, Hayes P, et al. Ku70 suppresses the apoptotic translocation of Bax to mitochondria. Nat Cell Biol 2003; 5:320329.

76 Chipuk JE, Kuwana T, Bouchier-Hayes L, et al. Direct activation of Bax by p53 mediates mitochondrial membrane permeabilization and apoptosis. Science 2004; 303:1010-1014.

77 Zamzami N, Maisse C, Metivier D, Kroemer G. Measurement of membrane permeability and permeability transition of mitochondria. Methods Cell Biol 2001; 65:147-158.

78 Cheng EH, Sheiko TV, Fisher JK, Craigen WJ, Korsmeyer SJ. VDAC2 inhibits BAK activation and mitochondrial apoptosis. Science 2003; 301:513-517.

79 Su J, Wang G, Barrett JW, et al. Myxoma virus M11L blocks apoptosis through inhibition of conformational activation of Bax at the mitochondria. J Virol 2006; 80:1140-1151.

80 Poncet D, Larochette N, Pauleau AL, et al. An anti-apoptotic viral protein that recruits Bax to mitochondria. J Biol Chem 2004; 279:22605-22614.

81 Arnoult D, Bartle LM, Skaletskaya A, et al. Cytomegalovirus cell death suppressor vMIA blocks Bax- but not Bak-mediated apoptosis by binding and sequestering Bax at mitochondria. Proc Natl Acad Sci USA 2004; 101:7988-7993.

82 Grinberg M, Schwarz M, Zaltsman Y, et al. Mitochondrial carrier homolog 2 is a target of tBID in cells signaled to die by tumor necrosis factor alpha. Mol Cell Biol 2005; 25:4579-4590.

83 Gross A. Mitochondrial carrier homolog 2: a clue to cracking the BCL-2 family riddle? J Bioenerg Biomembr 2005; 37:113119.

84 Esposti MD, Cristea IM, Gaskell SJ, Nakao Y, Dive C. Proapoptotic Bid binds to monolysocardiolipin, a new molecular connection between mitochondrial membranes and cell death Cell Death Differ 2003; 10:1300-1309.

85 Danial NN, Gramm CF, Scorrano L, et al. BAD and glucokinase reside in a mitochondrial complex that integrates glycolysis and apoptosis. Nature 2003; 424:952-956.

86 Morrison DK, Davis RJ. Regulation of MAP kinase signaling modules by scaffold proteins in mammals. Annu Rev Cell Dev Biol 2003; 19:91-118.

87 Harada H, Becknell B, Wilm M, et al. Phosphorylation and inactivation of BAD by mitochondria-anchored protein kinase A. Mol Cell 1999; 3:413-422. 